\title{
Role of Power Instrument in Rhinoplasty
}

\section{Original Article}

\author{
Usama Abdel Naseer', Omar Sabry², Nasser Abdelnasser ${ }^{3}$, Ahmed Nassar $^{4}$ \\ Department of ${ }^{1,2,4}$ Otolaryngology, Cairo University, ${ }^{3}$ ENT, Beni Suef University, Egypt.
}

\begin{abstract}
Background: Surgical correction of the bony vault is challenging part of rhinoplasty surgery. Over resection and dorsal irregularities are common complications of manual osteotomy that can occur even in the hands of practiced surgeons. Power-assisted instrumentation now offers a useful alternative for precise and controlled reduction of the bony vault. Patients and Methods: 40 patients were included in this study, Patients were divided into two groups: Group A (20 patients) was operated using conventional cold instruments.

Group B (20 patients) was operated upon using power instruments.

Results: On comparison between both groups regarding VAS cosmetic results, we found that the results were not statistically significant $(P$ value $=0.3)$. Although that the postoperative VAS-Cosmetic results of good and excellent improvement in group (A) was $65 \%$ compared to $75 \%$ in group (B).

Also on comparison between both groups regarding the assessment of preoperative and postoperative photography, we found that the results were not statistically significant $(P$ value $=0.4)$. Although that the patients showed good and excellent improvement were $60 \%$ in group (A) compared to $70 \%$ in group (B).

Conclusion: Power-assisted instrumentation system is minimally invasive and sharply decrease the incidence of complications associated with manual procedures.
\end{abstract}

Key Words: Micro rasp, micro saw, power assisted, rhinoplasty.

Received: 27 April 2021, Accepted: 16 July 2021

Corresponding Author: Ahmed Nassar, MD, Department of Otolaryngology, Cairo University, Egypt. Tel.: +201222903321, E-mail: Ahmednassar_79@hotmail.com

ISSN: 2090-0740, 2021

\section{INTRODUCTION}

The three main complaints during rhinoplasty consultations are a hump on lateral view, a big nasal tip, and a wide nose. Two of these three complains are related to the osseocartilaginous vault. ${ }^{[1]}$

Surgical correction of the bony vault is challenging part of rhinoplasty surgery. New techniques, combined with sophisticated cutting instruments, intraoperative icewater cooling, have greatly improved surgery of the bony vault. despite technical advances, Surgical correction of the bony vault still a well conceived and individualized treatment plan executed with meticulous precision and extreme care. $^{[2]}$

Over resection and dorsal irregularities are common complications of manual osteotomy that can occur even in the hands of practiced surgeons. Power-assisted instrumentation now offers a useful alternative for precise and controlled reduction of the bony vault. ${ }^{[3]}$

With Conventical osteotomes surgeons are not able to reduces or cutting nasal bones precisely as with powered instrumentation. Many types of powered instruments are available for use during rhinoplasty surgery, like microsaws, micro debriders, guarded burrs, reciprocating rasps and drills. ${ }^{[4]}$

The aim of this work is to describe powered micro saw osteotomy and powered rasping as an effective alternative to conventional hump removal.

\section{PATIENTS AND METHODS:}

A comparative prospective study that was conducted on 40 patients complaining of nasal hump attending The Outpatient clinic in ENT department in the period between November 2016 and August 2018. The study was approved by the scientific and ethical committee of our institution.

40 patients were included in this study, Patients were divided into two groups: Group A (20 patients) was operated using conventional cold instruments. 
Group B (20 patients) was operated upon using power instruments.

23 patients were females and 17 patients were males age from 18 to 38 years. All cases were primary rhinoplasty and no revision cases. All the patients were subjected to pre-operative assessment protocol including:

A detailed history, Full ENT, Head and neck examination including facial and nasal analysis. The nose is inspected different view. Assessment of skin envelope, and osseocartilaginous framework were noted. Digital palpation is also performed along the dorsum, sidewall, and the caudal septum. Intranasal exam begins with a nasal speculum.

Routine preoperative blood tests were requested, while CT scan was requested only when nasal and sinus disease was suspected. preoperative Photographic analysis using frontal, Basal and lateral views.

All cases done under general anesthesia.

\section{In group $[\mathbf{A}]$ :}

Hump removed used cold instrument in form of (NOLST TRENITÉ Osteotomes and JOSEPH Raspatory), 15 cases done through closed technique and 5 cases done through open approach, Septoplasty done in 17 cases, and Out fracture of inferior turbinate done in 13 cases

\section{In group [B]:}

Hump removed with powered instrument in form of (micro saw hand piece with a maximum speed of 20,000 RPM (Racing Performance Machines). Micro compass saw blades (18 and $22 \mathrm{~mm}$ ), micro rasp head. 13 cases done through closed technique and 7 cases done through open approach, Septoplasty done in all cases, Out fracture of inferior turbinate done in 16 cases.

Follow up by clinical examination and photography at period range from 5 to 10 month.

\section{Assessment was based on:}

Comparisons between the preoperative photograph and the postoperative photograph taken at the final follow-up. According to this, Outcomes

were classified as:

$(0=$ No change $)(1=$ Fair $)(2=$ Good $)(3=$ Excellent $)$

Subjective analysis for aesthetic score using Visual Analogue Scale (VAS) for their symptom. Aesthetic scores are plotted from 0 to 4 where:
$(0=$ no improvement $)$

$(1=$ mild improvement $)$

$(2=$ moderate improvement $)$

$(3=$ good improvement $) \quad(4=$ excellent improvement $)$

Postoperative history was reviewed to assess complications, including postoperative infection, postoperative deformity (e.g., saddling or notching), or incomplete correction.

All the results were tabulated and statistically analyzed

\section{RESULTS:}

40 patients with nasal hump deformity. There were 23 (57.5\%) females and 17 (42.5\%) males. Patients ranged in age between 18 to 38 years.

\section{Group A:}

This group included 20 patients with nasal hump operated using manual hump resection and rasp. This group included 15 females and 5 males with age ranges from 18 to 38 years with Mean age $=27.3$.

\section{Before treatment:}

Those patients had different complaints. Twenty patients were complaining of cosmetic disfigurement $(100 \%)$, thirteen patients of them with nasal obstruction $(65 \%)$, two patients of them with allergic symptoms (2\%) and one patient of them with epistaxis $(0.5 \%)$.

\section{After history taking and examination:}

17 patients $(85 \%)$ showed history of trauma, 17 patients of them $(85 \%)$ with deviated septum.

\section{After treatment:}

The postoperative VAS of Cosmetic results showed that

3 cases (15\%) with no improvement

4 patients with moderately improved (20\%)

5 patients showed good improvement (25\%)

8 patients (40\%) with excellent improvement.

On comparison between the preoperative and postoperative photographs there were 3 patient with no improvement $(15 \%), 5$ patients with fair improvement (25\%), 4 patients $(20 \%)$ with good improvement and 8 patients $(40 \%)$ with excellent improvement. (Table 1)

\section{Group B:}

This group included 20 patients with nasal hump treated with the use of power instrument. This group included 12 males and 8 females with age ranges from 18 to 35 years with Mean age 26.5. 
The postoperative VAS-Cosmetic results showed that

2 patients with no improvement(10\%).

3 patients were moderately improved (15\%).

5 patients showed good improvement (25\%).

10 patients with excellent improvement (50\%).

On comparison between the preoperative and postoperative photographs satisfaction there were two patients $(10 \%)$ with no improvement, four patients with fair improvement $(20 \%)$, five patients $(25 \%)$ with good improvement and 9 patients $(45 \%)$ with excellent improvement. (Table 2) (Figure 1).

On comparison between the results obtained from the photographic assessment and that from patient satisfaction we found that patient satisfaction higher than results obtained from the photographic assessment, indicating that patient satisfaction is the greater than expected from the photographic assessment.

On comparison between both groups regarding demographics, the age and sex weren't statistically significant.

On comparison between both groups regarding VAS cosmetic results, we found that the results were not statistically significant $(P$ value $=0.3)$. Although that the postoperative VAS-Cosmetic results of good and excellent improvement in group (A) was $65 \%$ compared to $75 \%$ in group (B).

Also on comparison between both groups regarding the assessment of preoperative and postoperative photography, we found that the results were not statistically significant $($ Pvalue $=0.4)$. Although that the patients showed good and excellent improvement were $60 \%$ in group (A) compared to $70 \%$ in group (B) (Table 3 ).

Table 1: Comparison between photographic assessment and patient satisfaction in group A

\begin{tabular}{|c|c|c|c|c|c|c|c|c|c|}
\hline \multicolumn{10}{|c|}{ Photograph } \\
\hline \multirow[t]{3}{*}{ P Value } & \multicolumn{4}{|c|}{ Excellent $(\mathrm{n}=10)$} & \multicolumn{2}{|c|}{ Good $(n=5)$} & \multicolumn{2}{|c|}{ Fair $(n=5)$} & \\
\hline & $\%$ & & $\mathrm{~N}$ & & $\%$ & $\mathrm{~N}$ & $\%$ & $\mathrm{~N}$ & \\
\hline & & & & & & & & & VAS \\
\hline \multirow[t]{4}{*}{$<0.001 *$} & 0.0 & 15 & & 3 & 0.0 & 0 & 15.0 & 3 & No imp \\
\hline & & & & & & o & 20. & 4 & Mod imp \\
\hline & 0.0 & & 0 & & 25 & 5 & 25.0 & 5 & Good imp \\
\hline & 40.0 & & 10 & & 50 & & 40 & 8 & \\
\hline
\end{tabular}

Table 2: Comparison between photographic assessment and patient satisfaction in group B.

\begin{tabular}{lccccccc}
\hline \multicolumn{2}{c}{ Photograph } \\
\hline P Value & \multicolumn{2}{c}{ Excellent $(\mathrm{n}=9)$} & Good $(\mathrm{n}=5)$ & Fair $(\mathrm{n}=4)$ & No Imp $(\mathrm{n}=2)$ \\
& $\%$ & $\mathrm{~N}$ & $\%$ & $\mathrm{~N}$ & $\%$ & $\mathrm{~N}$ & VAS \\
& & & & 10 & 2 & No imp \\
$<0.001^{*}$ & $45 \%$ & 0 & $25 \%$ & 0 & 15 & 3 & Mod imp \\
HS & 0.0 & 0 & 00 & 0 & 25 & 2 & Good imp \\
& 00.0 & 00 & 00 & & 50 & 10 & Excellent impr \\
\hline
\end{tabular}

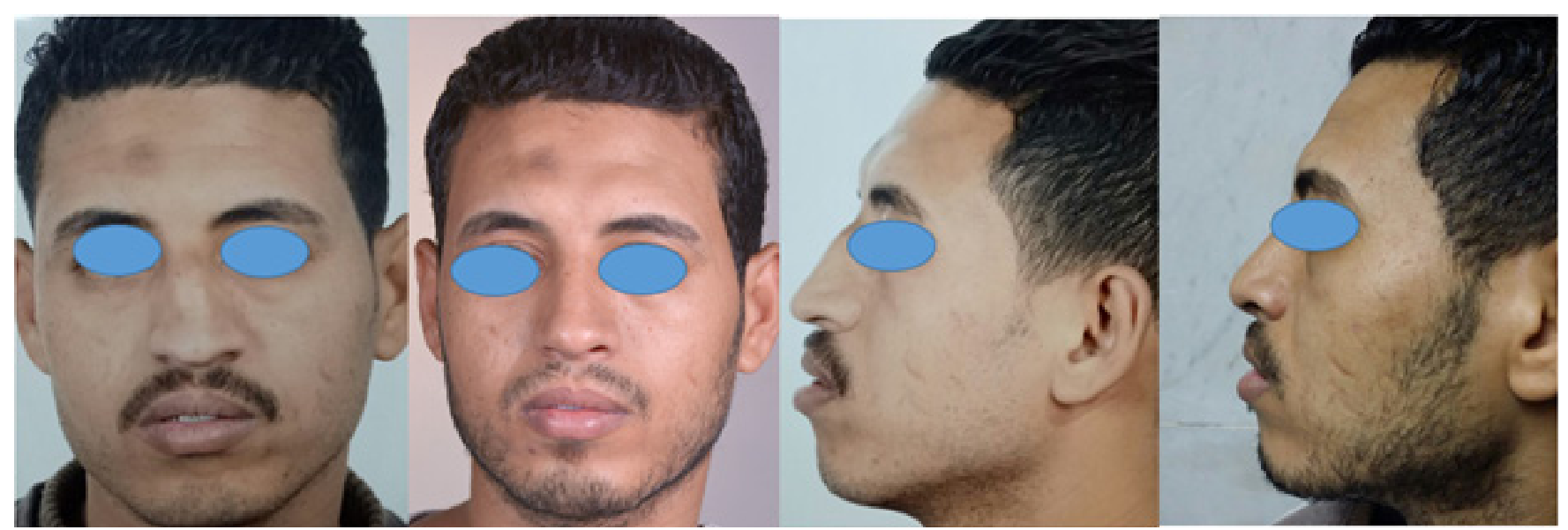

Figure 1: pre- operative \& post-operative photo 
Table 3: Comparison between both groups regarding VAS \& photograph.

\begin{tabular}{|c|c|c|c|c|c|}
\hline \multirow[t]{2}{*}{$\mathrm{P}$ value } & \multicolumn{2}{|c|}{ Group B $(n=20)$} & \multicolumn{2}{|c|}{ Group A $(n=20)$} & \\
\hline & $\%$ & $\mathrm{~N}$ & $\%$ & $\mathrm{~N}$ & \\
\hline \multirow{6}{*}{$\begin{array}{l}0.3^{*} \\
\mathrm{NS}\end{array}$} & & & & \multicolumn{2}{|r|}{ VAS } \\
\hline & 10.0 & 2 & 15.0 & 3 & No improvement \\
\hline & 15.0 & 5 & 20.0 & 4 & Moderate improvement \\
\hline & 25.0 & 9 & 25.0 & 5 & Good improvement \\
\hline & 50.0 & 11 & 40.0 & 8 & Excellent improvement \\
\hline & & & & & Photograph \\
\hline \multirow{4}{*}{$\begin{array}{l}0.4^{*} \\
\mathrm{NS}\end{array}$} & 10.0 & 2 & 15.0 & 3 & No change \\
\hline & 20.0 & 4 & 25.0 & 5 & Fair \\
\hline & 25.0 & 5 & 20.0 & 4 & Good \\
\hline & 45.0 & 9 & 40.0 & 8 & E30940134 \\
\hline
\end{tabular}

*Chi square test

\section{DISCUSSION}

The bony framework of the nose is essential for both nasal shape and function. The bony framework consist of paired nasal bones and frontal process of the maxilla. The surgical approach to nasal dorsum still challenging and is frequently debated among rhinoplasty surgeons. ${ }^{[5]}$

Correction of nasal bony vault is an essential part in rhinoplasty surgery, whether reducing the dorsal profile line or narrowing the base bony width. Last years, new insights into our understanding of nasal anatomy, how we analyze bony vault deformities, and the introduction of new surgical techniques. Therefore, a reassessment and overview of bony vault surgery appears justified. ${ }^{[6]}$

The power instrument is Highly precise cut, Safe with effortless cutting, Less swelling and bruising, More natural results, Reduced post-operative pain and Fast recovery. ${ }^{[7]}$

In our study we operated on 20 patients (group B) using power instrument to correct their nasal hump. We used power micro saw and rasp through an open and closed approach rhinoplasty technique.

Lopez et al in 2005 using Powered oscillating rasps for reducing dorsal bony humps during rhinoplasty, and it has been suggested that powered osteotomes may reduce tissue trauma when performing nasal osteotomies. Powered rasp has also been used to reduce dorsal bony humps and correct boney irregularities. Although septal spurs have traditionally been excised manually, powered instrumentation has proved useful in this area as well. ${ }^{[8]}$

our results mimic those obtained from Davis and Raval in 2003 Use Power-assisted instruments for bone removal in 105 rhinoplasties cases. in which 102 obtained satisfactory refinement of the nasal dorsum in primary surgery with three cases required revision surgery. Ultimately, all 105 patients achieved satisfactory surgical results. No other surgical complications were observed. ${ }^{[9]}$

Avşar Y. in 2009 performed 332 primary rhinoplasty and septorhinoplasty procedures. Bony Hump removed with powered micro-saw was performed in 259 cases including 127 with moderate humps ( 3 to $4 \mathrm{~mm}$ ), 112 with large humps ( 5 to $6 \mathrm{~mm}$ ), and 20 with very large humps ( 7 to $8 \mathrm{~mm}$ ). Satisfactory results were maintained in all cases, with minimal revision in 10 cases and no complication. ${ }^{[10]}$

Powered instrumentation has proven to be a versatile and precise method of modifying the nasal dorsum. they may be used to smooth the edges of the "open roof" after osteotomy or to reduce the entire hump in a more precise fashion. Powered instrumentation are less traumatic to the soft tissue envelope.

It is better to be used with a light touch for slow, incremental adjustments. The powered rasps and nasal dorsum drills may decrease the incidence of bony dorsal irregularities after rhinoplasty. ${ }^{[7]}$

Also our result suggest manual rasps and osteotomes, can be traumatic instruments, resulting in tissue oedema and bruising. The feather touch rasp is one of the powered instruments developed in recent years to improve precision and technical ease while preventing tissue trauma. The powered rasp has been frequently used for hump reductions.

In our study show only 4 cases with dorsal irregularity with conventional osteotome but not seen with Power-assisted bone removal so it is a useful adjunct for bone removal in cosmetic rhinoplasty. 
Our study confirms the benefits of powered instrumentation for patients with bony humps and bony asymmetries. Being less traumatic for the skin envelope, it is suitable for revision cases, old ages, and weak nasal bones. also, Complications associated with power-assisted bone removal were rare.

The outcome after surgery in patients with nasal hump group B was significantly better (75\% excellent and good results) compared to the group A (65\% excellent and good results). So our study suggest like other studies the effect of use power instrument for hump removal with precise execution of blunt force osteotomies. Over resection, asymmetry, and comminution are among the recognized complications of manual osteotomy that can occur even in the hands of practiced surgeons. Power-assisted instrumentation now offers a good alternative for precise and well controlled reduction of the nasal hump. Powered-rasps have been used mainly for small humps and to control bony irregularities while Powered micro-saw used in cases of larger nasal humps.

\section{CONCLUSION}

Power-assisted instrumentation can provide an alternative to manual osteotomy in the reduction bony humps. This system is minimally invasive and sharply decrease the incidence of complications associated with manual procedures. Precise control in shaping the osseous vault enables the surgeon to predetermine the amount of bone reduction.

\section{CONFLICT OF INTEREST}

There are no conflicts of interest.

\section{REFERENCES}

1. Daniel RK, Palhazi P. Osseocartilaginous vault. In: Daniel RK, Palhazi P, eds. Rhinoplasty: An Anatomical and Clinical Atlas. New York, NY: Springer; 2018:113-163
2. w. gubisch Osteotomies in Primary Rhinoplasty. In w. gubisch, mastering advanced rhinoplasty, Springer Berlin Heidelberg ; 2017:476.

3. Kaluskar S.K., Evolution of rhinoplasty. Indian J- Otolaryngol- Head Neck surg. 2008; 69: 101-105.

4. Foda H., External rhinoplasty for the Arabian nose: Acolumellar scar analysis. Anesthetic plastic surg, 2004 ;28(5):P312-316.

5. VanKoevering KK, Rosko AJ, Moyer JS. Osteotomies Demystified. Facial Plast Surg Clin North Am. 2017 May; 25(2):201-210. doi: 10.1016/j.fsc.2016.12.005. Epub 2017 Feb 21. PMID: 28340651.

6. Gerbault O, Daniel RK, Palhazi P, Kosins AM. Reassessing Surgical Management of the Bony Vault in Rhinoplasty. Aesthet Surg J. 2018 May 15;38(6): 590-602. doi: 10.1093/asj/sjx246. PMID: 29432541.

7. Becker D.G. Technical considerations in powered instrumentation. Otolaryngol Clin North Am, 1997; 30:421.

8. Lopez MA, Westine JG, Toriumi DM. The role of powered instrumentation in rhinoplasty and septoplasty. J Long Term Eff Med Implants. 2005;15(3):283-8 doi: $\quad 10.1615 /$ jlongtermeffmedimplants.v15.i3.50. PMID: 16022639 .

9. Davis RE, Raval J. Powered instrumentation for nasal bone reduction: advantages and indications. Arch Facial Plast Surg. 2003 Sep-Oct; 5(5):384-91. doi: 10.1001/archfaci.5.5.384. PMID: 12975135.

10. Avşar Y. Nasal hump reduction with powered micro saw osteotomy. Aesthet Surg J. 2009 Jan-Feb; 29(1): 6-11. doi: 10.1016/j.asj.2008.10.009. PMID: 19232999. 